\title{
A Model for Value-Based Selling: Enabling Corporations to Transition from Products and Services Towards Further Complex Business Models
}

\author{
John Lindström \\ ProcessIT Innovations, Luleå University of Technology, \\ 97187 Luleå, Sweden. \\ Received 14 August 2014; Accepted 14 August 2014 \\ Publication 19 September 2014
}

\begin{abstract}
The paper introduces a tested and verified model for value-based selling, based on an action research approach spanning multiple business models during five cases in a sequence at different corporations. The sales model has been verified to support sales of products, services, solutions and Functional Products, enabling corporations to add additional and more complex business models by being able to quantify and visualize the perceived customer value created/captured. Thus, the sales model can further facilitate a transition from sales of products or services towards sales of offers, based on further complex business models, where customer values created increasingly originate from intangibles that are part of the offer. Such a transition may be necessary for corporations acting on global markets to achieve sustainable competiveness and profitability.
\end{abstract}

Keywords: Functional Products (FP), Industrial Product-Service Systems $\left(\right.$ IPS $^{2}$ ), product, Product-Service Systems (PSS), sales model, services, solutions, tested, tool, value-based selling, verified.

Journal of Multi Business Model Innovation and Technology, Vol. 1, 67-98.

doi: 10.13052/jmbmit2245-456X.213

(c) 2014 River Publishers. All rights reserved. 


\section{Introduction}

The background and motivation for this paper is that during the sale of products, services and solutions (i.e. products combined with services) at several corporations in a business-to-business setting, no adequate sales model to enable quantification of the perceived full customer value could be found. As sales representatives in most cases try to sell customer value instead of a product or service, sales representatives need to be able to model and estimate what the actual customer value will be. This is an even more apparent issue in further complex business models used, for instance, within the manufacturing industry. Such models may include: Product-Service Systems/Industrial Product-Service Systems (PSS/IPS ${ }^{2}$ ) (Meier et al, 2010), Total-Care Products (Alonso-Rasgado et al., 2004), Functional Sales (Stahel, 1997) or Functional Products (FP) (Brännström et al., 2001; Lindström et al., 2012, in press), where the customer values increasingly originate from intangibles that are part of the offer and make the customer values harder to find/identify, analyze/understand, estimate, model/simulate and quantify. However, in a tough business climate, this would be of crucial importance to close business deals by convincing mid and top management (and, in some cases, boards of directors) by estimating and modelling/simulating the actual perceived customer value which would be enabled by the business deal or investment.

There is plenty of marketing/sales management literature, e.g. Rackham \& DeVincentis (1999) and Anderson et al. (2007), concerning the importance of selling value as opposed to selling the actual products, services, or solutions, etc. According to Töytäri et al. (2011) and Terho et al. (2012), there is a lack of tangible research on tested and verified sales models used for value-based selling spanning offers based on business models such as, e.g., products, services, solutions and the additionally complex ones mentioned above. However, there are some relevant examples or approaches such as, e.g.; Hanan \& Karp (1991) proposing the use of the Net Present Value (NPV) method in value-based selling, Terho et al. (2012) conceptualizing value-based selling in three dimensions, Töytäri et al. (2011) suggesting a process for valuebased selling, and Van Ostaeyen et al. (2012) outlining a value-price-cost framework adapted for a PSS context.

Regarding the mutual aspect of value co-creation, involving both the provider and the customer, Grönroos (2007) states that the process for creating value for customers is different in a relationship-oriented perspective versus exchange- or transaction-oriented perspectives, and that the focus should be on the customers' outcome of the production (i.e. value-creating or 
value-formation) process rather than the distribution of value to customers. Kotler (2000) adds that it is necessary to investigate the customer value delivered, and D'Andrea (2005) posits that sales professionals need to demonstrate value and highest return-on-investment (ROI) to customer through the sales process enabling the customers to make the lowest total cost decision. D'Andrea $(2005, \mathrm{p} 20)$ further proposes that during a sales negotiation the seller should establish the value "and then put their 'high value, high price' offer on the table" to take control of the sales process and compile a more profitable deal. However, how to establish and quantify the value, and put an attractive price on it, is a question that needs further investigation. One way to convey the value to customers during a sales process is to describe the value in a qualitative manner, e.g. using words and figures. However, a quantitative way to convey the value is often preferred by decision makers on the buying side in order to be able to justify business deals or investments. Thus, hard numbers in estimates generally have an advantage over words and figures in a business case presented to decision makers. In addition, D' Andrea (2005) also mentions that a customer's hidden or underlying needs should be investigated.

The PENG-model (Dahlgren et al., 1997, 2000, 2006) provides a model and process to investigate the ROI using the direct, indirect and hard-toestimate income/benefits (i.e. customer value) potentially generated by an investment. Originally, the PENG-model was aimed at providing decision support for IT-investments, but the model is applicable in other areas as well.

Research by Liozu et al. (2012) on value-based pricing shows that the corporations investigated practicing cost- or competition-based pricing approaches show poor understanding of value-based pricing. They further state that few industrial firms have adopted value-based pricing, and that cost- and competition-based pricing dominates the pricing strategies in practice. Notably, according to Liozu et al. (2012), there seems to be a wide array of various definitions of value-based pricing, which may confuse the understanding of the concept - and thus how to implement it. Johansson et al. (2012) assert that corporations struggle with implementing value-based pricing strategies and that their research indicates that more than 80 per cent of corporations practice pricing primarily based on cost. They further posit that consideration must be given to e.g., processes, routines and resources involved. Little (2012, p103) adds that to achieve successful selling, "customers must see sellers as 'trusted advisors" connecting with the customer's value base. Thus, not only the customer's problems and wanted customer values must be understood. Kowalkowski \& Kindström (2010) state that, when moving into PSS offerings, manufacturing firms need to be able to visualize 
the value of the offering. They assert that visualizing value becomes harder when moving into integrated offers such as PSS compared to when offering products, since there is a need to translate intangibles into selling points. They further add that additional factors such as the offering's complexity, novelty on the market, importance to the customer's business and process, and degree of intangibility impact on the need for visualization. Kowalkowski \& Kindström (2010) propose a value visualization framework for PSS with four steps, whereas Anderson et al. (2007) outline a generic five-step process for customer value management. Thus, visualization and management of customer value are important aspects of value-based selling; however, realizing and maintaining them on a long-term basis is not always easy.

A value-based selling ability enables a corporation to sell a large variety of offerings, particularly where inherent complexity and unique values in the offerings (and their intangibles) make them hard to compare against competitors' offerings. Casadesus-Masanell \& Ricart (2010) stress the need to understand how to innovate business models to improve the ability to create and capture value. An ability to add new or additionally complex business models may be necessary for corporations to stay innovative, competitive and profitable over time. Thus, as value-based selling seems attractive for many corporations, 'how to go about it' is a highly relevant question. Some examples or approaches relevant for this paper are presented below. The NPV-method used for value-based selling is brought up by Hanan \& Karp (1991), who use a traditional cost-benefit analysis and posit that the price becomes a floating point driven by value that automatically renegotiates itself around the value that drives it. However, using the NPV-method alone to calculate the ROI in value-based selling has a weakness in that only the visible cash flows are commonly accounted for as part of the customer value. Terho et al. (2012) conceptualize value-based selling in three dimensions comprising: understanding the customer's business model, crafting a value proposition and communicating the customer value. Further, Töytäri et al. (2011) aim to bridge the theory-to-application gap in value-based selling by proposing how to model customer-desired versus perceived value in a process for value-based selling. On the down-side of value-based selling, Parvinen et al. (2011) assert that many companies struggle with development of value-based pricing and related sales skills (e.g. meeting methodology, order of argumentation and sophistication of value calculation), although there is management consensus that value-based selling is needed. In addition, to overcome customers' potential scepticism towards value-based selling, Töytäri et al. (2011 p493) add that in order to convince the customers, 
the selling firms need to "support their sales efforts with tangible evidence of the value they can deliver to their customers, both pre-purchase as well as post-purchase".

There is a gap in literature on tested and verified models for value-based selling taking into account and quantifying the full customer value perceived (i.e. not only the direct value in the form of visible cash flows) while selling products, services and solutions, as well as additionally complex offerings based on business models such as PSS/IPS ${ }^{2}$ or FP. The issue addressed in this paper is how such a sales model can be embodied to support valuebased selling enabling corporations to quantify the perceived full customer value. As value-based selling is practised by corporations, it can be assumed that there are practices, models, etc. used, which are kept confidential and seen as intellectual property. Thus, these practices and models are commonly not public and may not be general enough to be used by other corporations. The purpose of the paper is to test and verify a sales model supporting multiple business models, developed using an action research approach during five cases and implemented in a tool, enabling value-based selling providing quantified information regarding the potential value rendered by the business deal or investment to decision-makers on the buying side (i.e. mid and top management and/or boards of directors).

\section{Methodology}

The sales model, which has been implemented in a tool, has been developed during a sequence of cases conducted between 2000 and 2013 at five different corporations. The development has spanned less complex business models (i.e. products, services and solutions) towards an additionally complex one (i.e. FP). Mid and top management, sales managers and sales representatives in the case corporations have participated in this action research effort during the development of a sales model for value-based selling. Each of the cases comprised a number of different sales or investment projects. Below, the case corporations are briefly described:

- Case 1 - an international public limited company selling IT-securityrelated products (i.e. software and hardware) and services. The case involved the Nordics sales team (i.e. Sweden, Denmark, Finland and Norway).

- Case 2 - an international privately held corporation selling IT-securityrelated products (i.e. software) and services. The case involved key account managers targeting EMEA and US markets. 
- Case 3 - an international privately held corporation providing cloud services and complementary professional services. The case involved key account managers targeting EMEA and US markets.

- Case 4 - a public sector real-estate corporation investing in land and buildings. The case involved investment assessments within Sweden.

- Case 5 - a privately held Swedish-based manufacturing corporation, Infrafone $\mathrm{AB}$, selling infra sonic soot cleaning for large chimneys or economizers (energy extraction from hot smoke) including products, services, solutions and FP. The target markets were mainly the Nordics and Europe, as well as markets world-wide where appropriate. During this case the sales model and tool were further developed and also formally tested, verified and evaluated over the course of one year and covered more than forty sales projects. The activities included the CEO, sales manager and three sales representatives (i.e. all involved in the sales process), though not technical expertise.

In each of the five cases an action research approach has been utilized. Action research is suitable for development of models, methods or processes, etc. due to its iterative and reflective nature as well as the researcher's participation in the cases and their organizational changes. However, a spiral model with a gradual refinement over time could have been used as well. Action research has been defined as "a participatory, democratic process concerned with developing practical knowing in the pursuit of worthwhile human purposes, grounded in a participatory worldview which we believe is emerging at this historical moment. It seeks to bring together action and reflection, theory and practice, in participation with others, in the pursuit of practical solutions to issues of pressing concern to people, and more generally the flourishing of individual persons and their communities" (Reason \& Bradbury, 2001).

Characteristics of action research are that action researchers act in the studied situations, that action research involves two goals; a) solving the problem (the role of the consultant) and b) making a contribution to knowledge (the role of the researcher); that action research requires interaction and cooperation between researchers and the client personnel, and that action research can include all types of data gathering methods (Gummesson, 2000). In this research the researcher has acted as an expert, consultant in the role of case leader, or advisor, being responsible for the three of the five cases that also have involved additional personnel at the participating corporations. According to Coughlan et al. (2004), the action research approach comprises 
four phases: diagnosing, planning action, taking action and evaluating the action in relation to a certain context and with a specific purpose. The above was embodied in the following iterative and reflective case management methodology (see Figure 1).

In Figure 1, the four action research phases are outlined inside of each case. The phases overlap, since some issues remain unresolved before moving on to the next phase. In addition, there are also feedback loops within each phase as often there was a need to resolve issues/problems that were not solved properly at the end of the phase before moving on.

Since the cases were conducted in a sequential order, the results such as: knowledge, experiences, sales model, awareness of problems and challenges from the previous case(s), were used when starting up the next case. This approach allowed for systematic replication and refinement both regarding methodology, and execution of research and action efforts. After the end of the last case (the fifth one), a formal evaluation of the sales model was made.

The original development of the sales model, which has been implemented as a sales tool in Microsoft Excel, started during sales projects where additional explanations of the potential value from customers' investments in security software and hardware were required to convince the customers' mid and top management that the potential business deals or investments were sound and would provide a targeted level of ROI. During the course of applying the sales model in sales projects, new aspects of income/benefits (i.e. customer value) were added to the original sales model. The first two cases involved improving and further developing the sales model and its implementation in the tool. The third case improved the visualization of the sales model's output, e.g., changing the user interface by using Excel's inherent ability to program different cells to automatically show different colours, i.e. green for positive, red for negative and light green for neutral (0), for the result. Additional improvement to provide flexibility for input and necessary changes

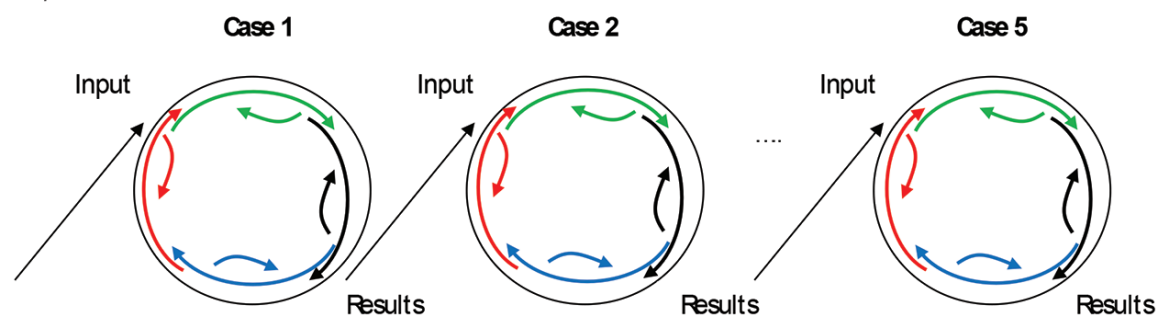

Figure 1 Case management methodology 
or additions to the sales model were further implemented. In the fourth case, further sales model flexibility was added and subsequently implemented in the sales tool. Finally, during the fifth case the sales model, described later in section 4, was adapted for the context, templates of the model and its tool were customized for different industries (or customer segments/scenarios), and then tested and verified.

The first design criterion for the sales model (and its implementation in a tool), was that the output should mainly target decision-makers on mid/top management and board levels; however, low/mid/top level management should also be able to understand and participate in the collection of the input needed. A further design criterion was that the sales model and tool should be easy to learn, understand and modify input/output-wise by sales representatives. The action was planned to lead to permanent change in the case organizations' sales process and that the sales model implemented in the tool should be used during the sales process when appropriate.

Reliability was supported by results that were replicated/iterated through five cases to reach stability using an action research approach. Further, during the sequence of cases, validity was ensured by replicating the research and results between different corporations, locations, industries and issues using a systematic and cyclic process, multiple sources of information and high quality awareness.

Regarding generalizability of the results, the sales model has been tested in the following business model contexts: products, services, solutions and FP, and therefore the sales model seems to support both less complex as well as additionally complex business models and their offers. Further, various industries such as IT, real estate and manufacturing have been part of the research, and the sales model seems to work cross-industry as well.

To learn if the sales model was stable after the fifth case, that it met the design criteria and was ready to use in other contexts, a formal evaluation using the mixed-methods study model (Stufflebeam, 2001) combining qualitative and quantitative methods was selected. Standardized semi-structured interviews (qualitative) with open questions (Patton, 1990; Kvale \& Brinkmann, 2009) were conducted, allowing the respondents to give more detailed answers and add extra information where deemed necessary (Fontana \& Frey, 1994). The respondents were one key informant and 3 sales representatives from the last case, where the sales model and tool covered in section 4 were used. Further, rating scales (quantitative) from 1.00 to 10.00 were applied during the evaluation. The interviews and the rating scales gave an indication of whether the model was stable or needed further improvements. At the end 
of the interviews it was possible to comment on the questions or add any additional information needed. The notes and scores on the interview protocols were checked by the informants directly during the interviews to make sure all answers were correct and complete. It was also possible to contact the informants after the interviews to clarify or complement any answers.

The data from the interviews was then reduced and analyzed using matrices (Miles \& Huberman, 1994). The findings from the analysis of the evaluation are found in section 6 .

\section{Additionally Complex Business Models and Related Customer Values}

Moderate or disruptive innovation is necessary for most corporations to continuously be able to create value, stay in business and remain economically, ecologically and socially sustainable. The innovation can be embodied in many forms, and commonly one or more of the following areas are targeted: offer (and its potential technology, services or other constituents), manufacturing/production process, value chain (including supply-, distribution/delivery chains), networks/relations (partner-, SME- and research collaborations), business model(s), etc. Being one area of innovation, corporate business models generally aim to create value and sustainable competitive advantage in a defined market. Within this context, Chesbrough (2010) asserts that the choice of business model is crucial as "a mediocre technology pursued within a great business model may be more valuable that a great technology exploited via a mediocre business model" (p355). Further, Casadesus-Masanell \& Ricart (2010) point out the necessity to understand how to innovate business models in order to improve the ability to create and capture value. Thus, an adequate notion of the creation and capturing of value, i.e. how different inter-connected business model elements form the business logic required to do this, likely facilitates understanding of what is otherwise necessary for a successful and sustainable business model.

Below, Table 1 outlines the business model elements for a selection of relevant generic and more specialized business models. The generic business models can be applied for many business contexts to draw a "canvas" for a business model and its offer(s), for instance, products, services or solutions. The servitization business model describes how a product-based business seeks to increase the competiveness by moving towards a service-based model. 
76 J. Lindström

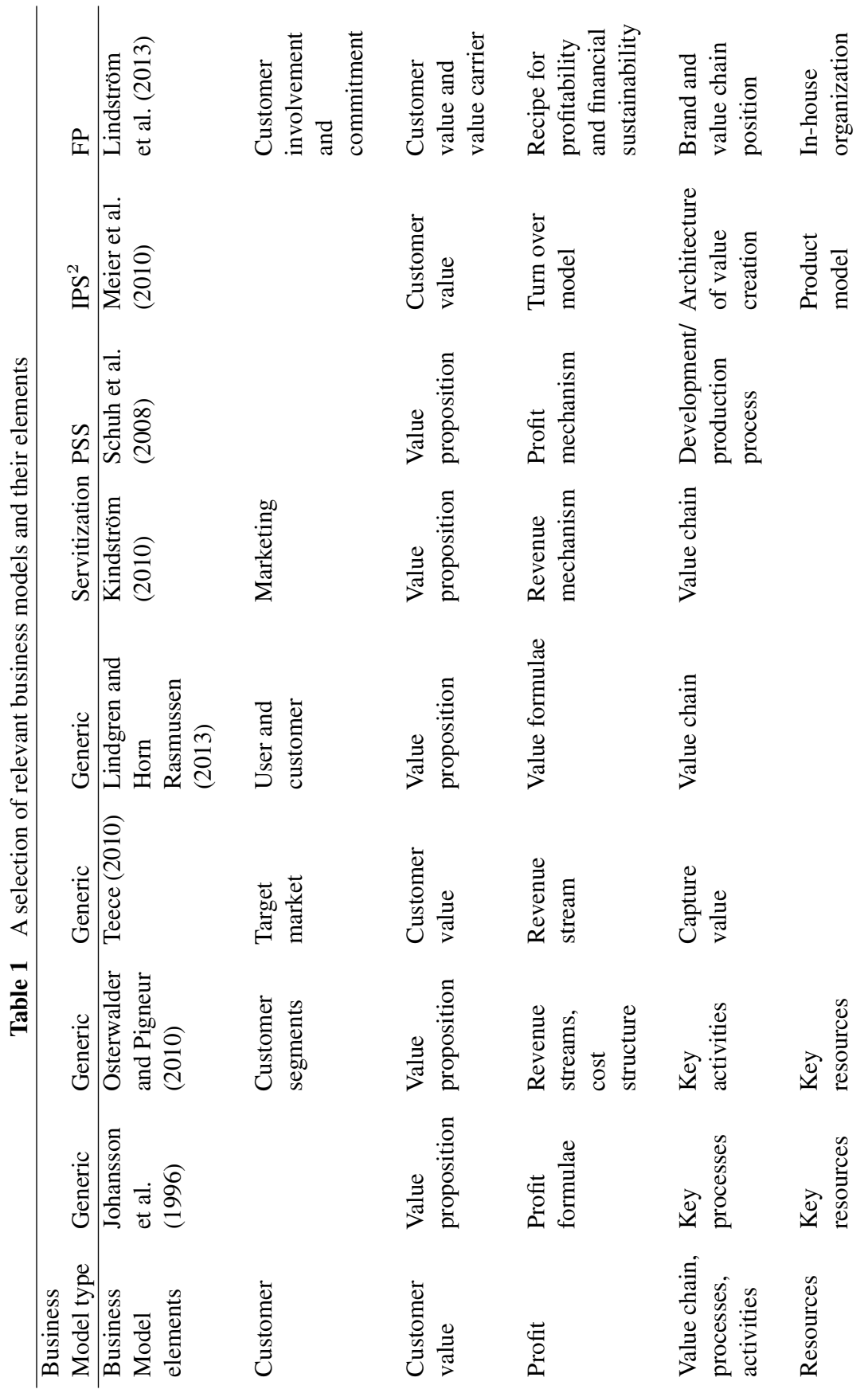




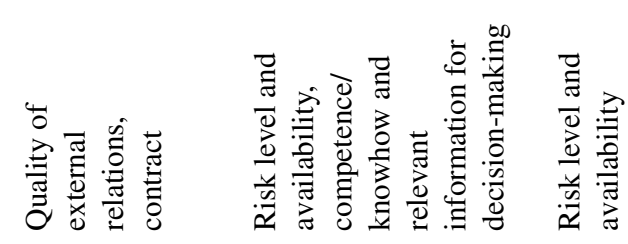

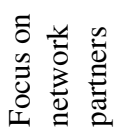

$\stackrel{0}{\stackrel{0}{\Xi}}$

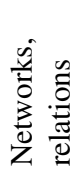

仓

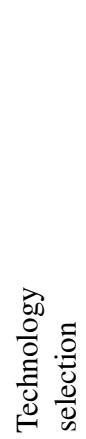

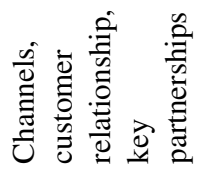

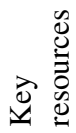

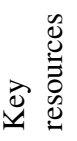

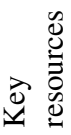

苗

泀

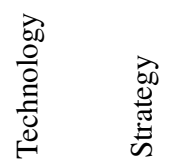


Due to their systemic nature the PSS, IPS ${ }^{2}$ and FP business models and their corresponding offers have an increased inherent additional complexity compared to if their constituents would be sold as parts, i.e. products, services, etc. As examples of the systemic nature, Meier et al. (2010) posit that IPS $^{2}$ enables function-, availability-, or result-oriented business, and Löfstrand et al. (2012) assert that FP enables productivity- or availability-based business. Both these examples indicate that the offers' constituents need to be highly integrated and well thought-through to operate on a long-term basis and that, to be able to manage the increased inherent complexity, the corresponding business models pose tough requirements on the providers in terms of the following elements: skills/competence, resources, relationships and technology, etc.

Table 1 indicates that the business model elements differ somewhat among the listed business models, which is interesting, particularly for the generic ones. However, common for all the business models is that they have some notion of the customer value embodied in, e.g. value proposition, customer value, as well as what carries the value.

According to Kaufman (1998), the principal elements used in customer value studies are classified as: esteem value or "want"; exchange value or "worth"; and utility value or "need", and that every buy decision includes one or all three of these elements. Further, Khalifa (2004) has identified three complementary models for categorization of customer value: to see customer value in exchange, customer value build-up, and customer value dynamics. These three models can be regarded as highly related and complementing each other. In addition, when the customer values have been found/identified, analyzed/understood, estimated, modeled/simulated and quantified, there is a need to be able to visualize the values prior to communicating them to customers (Terho et al., 2012).

For generic products, services and solutions, the customer value can vary considerably. Regarding the additionally complex business model such as PSS, IPS $^{2}$ and FP, there are some research outlining generic customer values. Listed below is an excerpt of such customer values found in recent publications:

- PSS/IPS ${ }^{2}$ - [more] customization and higher quality, asset management, utilization, less administration and monitoring, less environmental impact and improved sustainability (Baines et al., 2007), agreed-upon level of availability or result, eco-efficiency, enabling concentration on core competences and tasks, and performance improvement (Meier et al., 2010). 
- FP - total-care (Alonso-Rasgado et al., 2004), productivity and agreedupon level of availability (Löfstrand et al., 2012), paying for the delivered function only and risk transfer to provider can be regarded as essential. In addition, Lindström et al. (submitted) have in recent research identified a number of complementary FP customer values, such as: improved total-cost of ownership, improved cash-flow, less assets on balance sheet, increased revenue, decreased costs, improved performance or efficiency, etc.

The above customer values, whereof some are intangible in nature, can be categorized in terms of how they contribute to the income/benefit generation in a corporation. According to Dahlgren et al. (1997, 2000 and 2003), customer values can be divided into four groups depending on how they contribute in the income/benefit-generating processes: direct, indirect, hardto-estimate and unattained. The categorization and the process are further described in the following Section 4.

In Table 1, the business model element row with customer values becomes increasingly interesting. The interest lies in that the customer values not only need to be found/identified, analyzed/understood, estimated and modelled/simulated, but also (necessarily) quantifiable prior to being communicated to customers. Dahlgren et al. (1997 and 2000) propose a process for these activities (described on a high level in section 4); however, the authors do not explain how the results should be communicated to customers. If the customer values are not, or cannot, be communicated, it is harder to sell them in a competitive context. Elements in a business model are commonly related to each other; however, some are more obvious than others depending on if they are part of the value creation or support it (c.f. Lindström et al., 2013). Thus, some of the business model elements in Table 1 of direct interest for the customer value element include: customer, profit, value-chain/processes/activities and relationships. An example related to FP reveals that necessary elements are: customer involvement and commitment; recipe for profitability and financial sustainability; brand and value chain position; and quality of external relations as well as contract. Further, these four business model elements are especially necessary for successful value-based selling. Finally, it is essential to understand how the customers' profit (profit formulae) is embodied, and not just the own corporation's ditto, in order to sell value in a successful and sustainable manner. 


\section{A Model for Value-Based Selling}

Firstly, a sales model seen from a customer's perspective based on an $\mathrm{NPV}^{1}$-calculation, including a rate-of -return (i.e. the expected/wanted return on the investment in per cent) throughout the investment's economic lifetime, was developed including the expected costs and income/benefits (i.e. customer value) from an investment. The then recently introduced $\mathrm{PENG}^{2}$ model (Dahlgren et al., 1997, 2000) was used to estimate the net cash flow per year comprising: costs and the direct, indirect and hard-to-estimate income/benefits related to the potential investment. According to Dahlgren et al. (2003), there is also an additional fourth income/benefit, the unattained income/benefit, which indicates that additional income/benefit may accrue if the investment is implemented optimally. However, this fourth income/benefit will not be addressed in this paper. Dahlgren et al. (2003) further add that to reach the income/benefits (i.e. customer value), it is important to firstly agree upon: what creates the income/benefits, what needs to be conducted/accomplished to facilitate the creation, and how the income/benefits can be increased as well as verified. Those questions need to be answered during the PENG-model income/benefits finding process. Thus, the sales model introduced combines an NPV-calculation using input from the PENGmodel on an annual basis, i.e. the quantified net income/benefits (from income/benefit minus costs). Further, the NPV-calculation requires a rate-ofreturn, which preferably should be provided by the customer (otherwise, it can be derived using an analytical or iterative approach). Regarding investments, some investments have an initial base investment made at the start as well as residual value left at the end, which needs to be accounted for in the NPV-calculation when applicable.

The income/benefits included direct income/benefits, i.e. where hard figures are available to quantify such, and indirect income/benefits, i.e. where hard figures are not available and need to be revealed and transformed into quantitative figures to be able to be used in the NPV-calculation. Indirect

\footnotetext{
${ }^{1} \mathrm{NPV}$ - Net Present Value: NPV $=$ Residual value $/(1+\mathrm{p})^{\mathrm{n}}-$ Base investment + $\sum_{i=1}^{n} a_{i} /(1+p)^{i}$ where: $\mathrm{p}$ is discount rate or i.e. rate-of-return expected, $\mathrm{n}$ is the total number of periods (i.e. typically years), and $a_{i}$ is the net cash flow at time $i$. The base investment is commonly the initial investment cost and the residual value the value remaining from the investment at the end of the total period covered by the NPV calculation.

${ }^{2}$ PENG - Prioritera Enligt NyttoGrunder in Swedish. Translated into English - Prioritize According to Grounds of Income/Benefits. The PENG-model aims to identify and quantify the costs and income/benefit of an investment, to be able to quantify the residual net income/benefit (as an investment is sound and profitable).
} 
income/benefits may comprise the results of indirect effects from an investment, such as improvements in other processes or departments not directly targeted. Further, hard-to-estimate (or hidden) income/benefits need to be located, extracted and quantified. Possible hard-to-estimate ones are effects on brand, image, trustworthiness, etc. Subsequently, the income/benefits and costs should be put on a time line covering the total number of periods (i.e. typically years) the NPV is sought for. The annual net income/benefits depend on the level of implementation, usage as well as ability to efficiently use the investment made. The costs depend on the business model used to close the business deal. A product-oriented business model may have all or a majority of the costs in the beginning, whereas services may have a slight increasing annual cost due to cost-index if the volume is the same, and solutions may thus have a significant cost at the start related to products and other initial costs followed by the annual costs for services. Other types of business models may have different characteristics regarding the costs, like subscriptions or leasing, etc. PSS/IPS ${ }^{2}$ and FP can have different cost characteristics, which commonly depend on how strong a cash flow the provider has. Examples of possible cost characteristics for PSS/IPS ${ }^{2}$ and FP are an annual cost that follows cost index, or an increased initial cost (to cover development/manufacturing costs) followed by annual costs following cost index for as long as the PSS/IPS ${ }^{2}$ or FP is used by the customer.

Figure 2 shows how the PENG-model is used to find/identify, analyze/understand, estimate and quantify the resulting net income/benefits for each period (i.e. year) covered in the NPV-calculation. Thus, the identification, analysis, estimation and quantification must be made for each and every period. This may result in different net income/benefits and costs over time due to (un)foreseen circumstances.

The inherent property of the NPV-calculation, due to the rate-of-return, that preferably as much income/benefits as possible should accrue early and that the costs should arise as late as possible, makes the planning of the income/benefits versus costs an important aspect of the necessary teamwork involving the sales representative and customer personnel. A high level of transparency is required, since it is otherwise not possible to identify, analyze, estimate and quantify the customer's direct, indirect, hard-to-estimate income/benefits and costs. In addition, there may be additional income/benefits and costs related to other providers that need to be included to get the full picture of a potential business deal or investment. Töytäri et al. (2011) have recently outlined a similar view on the value desired and perceived by customers, but this view is not further elaborated in this paper. 


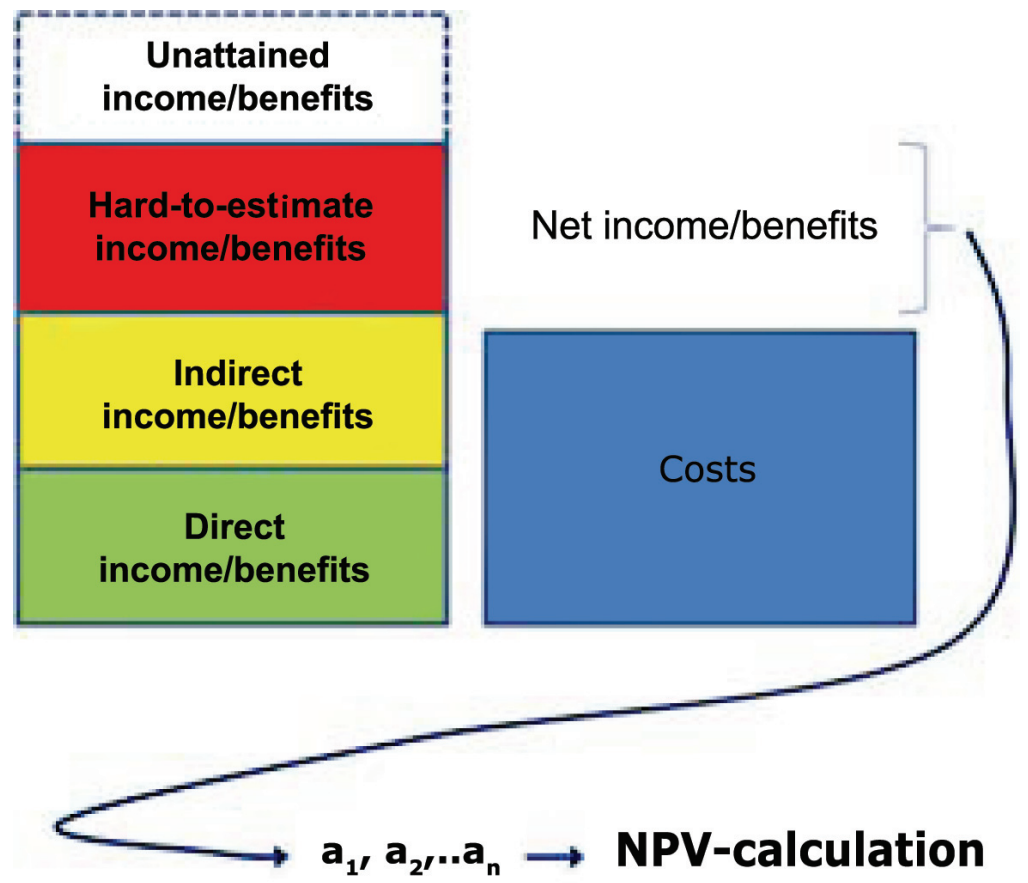

\section{For each period, i.e. from 1 to $n$, the net income/benefits $\left(a_{1}\right)$ are used as input to the NPV-calculation}

Figure 2 The PENG-model is used to generate periodic/annual input to the NPV-calculation

To do the above analysis and estimations of costs and income/benefits requires a close and transparent collaboration between the sales representative and the customer, to be able to find all necessary input to the sales model. Thus, a great deal of trust is required - and the sales model is not possible to use without trust and transparency. As it is not always possible to achieve trust at an early stage in a relation between a sales representative and a customer, the sales model should not be introduced until the necessary trust has been established.

The initial development of the sales model and its implementation in a tool was undertaken during the two first cases, which had similar contexts, and a basic sales model based on the PENG-model combined with an NPV-calculation took shape. Examples of direct income/benefits (for which hard figures were possible to extract) used during the first two cases were, 
e.g., that unnecessary software/hardware licences could be terminated, unnecessary tasks were eliminated, fewer personnel were needed for non-valuecreating tasks, or that more time could be devoted to value-creating tasks. Further, examples of indirect income/benefits during the first two cases were positive effects on areas other than the one mainly involved, improved working environment (less unnecessary boring routine tasks), the impact of an improved level of security (which is harder to calculate than perceived at a first glance (Magnusson et al., 2007)). In addition, examples of hard-toestimate ones were what effect the investment had on the corporate brand from increased trustworthiness, customer loyalty, employee satisfaction, etc.

The identification and estimation of direct and indirect income/benefits which an investment renders were during the third case further developed and refined in close cooperation with key customers. To enhance the visualization of the sales model's output, i.e. part of the tool's user interface, cells showing, e.g., NPV-values were programmed to automatically show red or green colours depending whether or not the potential investment was sound according to the expected rate-of-return. On occasion, customers wanted to lower the costs below an acceptable baseline for the case company. To mitigate such situations, a reciprocal open-book approach was successfully used to find acceptable levels of cost versus income/benefits for the customers as well as the case company. Although this was a side-step from value-based selling, to find a way towards closing the business deal, the sales model was also used during these situations as well.

During the fourth case, the sales model was modified to increase the flexibility and used to evaluate investments in real estate (e.g. buildings and land). However, less emphasis was placed on indirect and hard-to-estimate income/benefits during this case. This case also revealed an interesting aspect, in that the periods of time used for the calculations were very long, i.e. twenty-five and fifty years, compared to cases $1-3$, where normally four to six years were applied. Further, the visualization was augmented during this case regarding how long (years) before the investment turned "green" and reached the objective with a positive NPV.

In the fifth case, the sales team had before the case started already made a sales model, also implemented as a tool in Excel, to map out direct income/benefits and costs for customers. The existing sales model's purpose was to guide the sales process steps and information collection and produce a benefit calculation for the customer. The existing sales model was extended according to the PENG-model combined with the NPV-calculation and the experiences gained from the previous four cases. This allowed the sales 
representatives, together with the customers, to produce solid input to business cases for investments, showing what rate-of-return to be expected, as well as when in time the investment produced a neutral or positive NPV. This is of interest, since the earlier an investment achieves a neutral or positive NPV the more appealing it is to grant the investment. The economic life-times expected were between ten and thirty years, which provided context-dependant variations in the input to the sales model. The visualization of the sales model in the tool was designed to have an easy-to-understand user interface, be easy to modify and have an output area using colouring to enhance the visuals. The output section (and often the input section as well) was used as part of business cases presented for the customers' mid/top management and boards of directors. At the end of the fifth case, a formal evaluation was made with one key informant and the sales representatives to learn how the sales model and its implementation in a tool supported the sales of products, services, solutions and FP. In addition, interviews with two key informants were made on six occasions during the case to follow up on the progress and development of the sales model and tool.

\section{Modelling and Simulating the Effect of Different Cash Flow Schedules}

Prior to using the introduced sales model, corporations which intend to sell, for instance, solutions or offers based on additionally complex models, first need to analyze which parameters affect the own profitability of business deals and if these are sustainable over time in case the deal covers many years. Various methods can be used to do this (cf. Töytäri et al., 2011; Terho et al., 2012), but the PENG-model and NPV can be used for this purpose as well. Depending on the current cash flow and liquidity situation, various schedules for customer payments and own costs for development, production set up, manufacturing/assembly, maintenance/support, etc., should be estimated and used to model and simulate the long-term rate-of-return and annual cash flows. In a PSS/IPS ${ }^{2}$ or FP context with provision of a function, additional costs may need to be added throughout the duration of the business agreement to keep, for instance, a function operable at an agreed level of availability. When it is understood which parameters that have the largest effects, then a number of possible cash flow schedules can be further modelled and deemed good, acceptable or not acceptable. This has to be understood before entering a customer sales project, where the negotiation can be seen as started already when the collection of customer data regarding the perceived value 
(i.e. income/benefits) is initiated, as the sales model will reveal that payment is expected as well. Consequently, the sales team must be aware of this and be prepared to show one or more cash flow schedules that can be tried. If the cash flow schedules do not support the selling corporation's objectives regarding long-term profitability (which requires a corporate objective that can be used to calculate backwards to determine which profitability or rate-of-return each business deal should contribute) and liquidity, the business deal can do harm instead of doing good. Thus, the selling corporation should decompile the "customer price" or "payment set-up over time" of the business deal into periodic/annual cash flows and model these together with the own costs to determine the minimum customer price that can be charged, i.e. a baseline, for different cash flow schedules where the customers payments are distributed in various (good or acceptable) ways over time. During negotiations, the selling corporation should have their own internal, e.g., PENG/NPV-tool to check if the current business set-up corresponds to the internal requirements for business deals.

This paper is about value-based selling, implying that the customer should get the perceived value expected. However, this allows for flexible/variable pricing, i.e. value-based pricing (Nagle \& Hogan, 2007; Liozu et al., 2012). Of course, above the baselines regarding resulting rate-of-return and liquidity, the price can go up as long as the customer gets what is expected. Nagle \& Hogan (2007) stress that to avoid alienating the customer it is important to learn what the customer expects to pay for the value received. Thus, as a sales tactic, it is advisable to first collect as much information as possible about the customer's expected income/benefits prior to disclosing one or more proposed pricing and payment set-ups over time. In this way, if the flexible/variable pricing works out well, the customer pays an individual price (i.e. similar to the concept of perfect pricing) which depends on the customer's situation regarding generation of customer value (income/benefits) and expected rateof-return. This differs from cost-based pricing (although the cost should of course be part of the baseline for the value-based pricing) and competitionbased pricing (however, it is always necessary to have an idea of what prices the competitors charge for a potential similar value offered, so as avoid overpricing and losing the business).

The sales model enables sellers and customers to together estimate and model/simulate the effect of different cash flow schedules on the expected rateof-return/customer value generated for the customer. Such a model, combined with training on value-based selling, further helps to standardize the analysis of the customer value potentially generated by guiding the interaction and data 
collection during the sales process. Töytäri et al. (2011) support this insight, emphasizing that training is required and that the sales representatives need a diverse skill-set to be able to sell value.

A sales team needs to know what effect different cash flow schedules may have on their own business prior to working with the customer to find a mutual win-win situation. Selling corporations with a weak cash flow or small corporations may need to have schedules with larger customer payments early to be able to cover and sustain the initial costs. This is particularly important when moving into provision of additionally advanced business models such as selling offers based on PSS/IPS ${ }^{2}$ or FP. Then, from a selling corporation's perspective, it must be understood if a large up-front customer payment is needed to cover the initial costs, followed by a "flat-rate" increased with cost index over time during until the business agreement expires. Another option to charge for PSS/IPS ${ }^{2}$ or FP is to have a flat-rate, with periodic payments, increased with cost index over time, also covering the additional risks and investments made by the PSS/IPS ${ }^{2}$ or FP provider. Buying a PSS/IPS ${ }^{2}$ or FP, with provision of a function, should thus be more expensive than buying, for instance, a solution, since the provider retains ownership, assumes additional risks and financial burden, and is (depending on the agreement with the customer) responsible for maintaining the operation of the function at an agreed level of availability (Lindström et al., 2013).

\section{Findings}

Based on the evaluation, made during the fifth case, it seems necessary that sales representatives and sales management should be trained in value-based selling; they must learn how to explain the value and its implications to customers, as well as to time when to show customers the output from the sales model during the sales process. It seems to be hard to sell value as well as price value, and a pricing process rather than a pricing policy or strategy is necessary, since each sales project can be seen as unique. In such a pricing process, the sales management needs to be more active in the pricing compared to when pricing based on cost or competition. In addition, it is necessary to learn to understand when value-based selling does not work as well as what the customers are willing to pay for the value offered. Further revealed was that a provider needs to do his own homework and know, for each sales project, how various business options affect the own organization and which options are profitable and cash flow-wise sustainable over time. During the evaluation, it was emphasized that value-based selling requires that the customer and sales 
representative trust each other and that a necessary level of transparency, to share needed knowledge and collect the information related to income/benefits (i.e. customer value), is created and upheld throughout the sales project. A further point from the evaluation to consider is that it is necessary to maintain close dialogue with those who have the technical and economic responsibility for the potential value that can be created/captured. It is also advisable to inform the top management and to facilitate customer internal discussions. However, forcing decisions from top management (e.g. CEO, COO, CTO or $\mathrm{CFO}$ ) onto the responsible managers is not advisable, as it may cause resistance or, at worst, a "no-business-will-be-done-here" situation.

The sales model and its implementation in a tool provide a certain level of support for sales of products and services, as well as an additionally higher level of support to business models with a high level of complexity and where unique values, increasingly originating from intangibles, can be created and captured by customers. The sales model was perceived to provide good support to structure the sales process and its information collection/analysis together with customers, as well as to anchor the customer value and give an overview during the presentation of the offer to customers. Further, the sales model was considered by the sales representatives to be modern, necessary and give a professional impression of the provider. This gave the sales representatives encouragement and confidence. The sales model and its implementation in a tool were considered to support the sales representatives during the sales process, on a scale from 0.00 (low) to 10.00 (high), with an average of 8.00 (and a median 7.50 and a standard deviation of 1.41). The visualization of the sales model output in the tool provided, on a scale from 0.00 (none) to 10.00 (all), an average of 6.25 of all information the customers need to make a decision (median was 6.50 and standard deviation 0.96). The necessary additional information provided comprises technical documentation and the offer. Further, the sales model seemed to provide a higher level of support for small-sized customers who did not have adequate own competence, which many of the larger customers had, regarding calculation of ROI from investments. Hesitant customers also appreciated the visualization of the sales model output in their decision-making process. In addition, business agreements lasting longer than one year are better supported by the sales model than short agreements - and in particular agreements lasting from three to thirty years can benefit substantially from using the value-based selling model. One way to calculate/simulate the rate-of-return is to change it manually until the NPV approaches 0 (unless the tool has an implemented routine able to do this analytically or iteratively on demand). This way, the customer can learn what 
rate-of-return to expect (i.e. the quantified customer value). Since what exactly can or may happen in the future is hard to foresee, users of the sales model and tool need to be aware that the input used can change and thus affect the output. However, at the outset, a structured estimation/simulation is possible with the current knowledge and available input.

The rating scale outcomes show that the sales model provides good support during the sales process. The standard deviation was 1.41 in the first one, which can be explained by the fact that some industries or customer segments are more conservative than others regarding value-based selling, and that valuebased selling might not be applicable in some of the sales projects.

Another insight was that when a corporation's sales process covers many different areas or applications, the values inherent in those areas or applications can differ significantly - although it is the same solution or FP that is being offered. This required in the last case that each area or application had its own specific master template of the model/tool developed, which was subsequently slightly adapted to the actual sales project or sales process instance in question.

Regarding the design criteria, the evaluation shows that the sales model and its implementation in a tool are stable and work well during the sales process to involve the customer's low/mid/top management levels in the information collection, and that the visualization of the output from the sales model is easy to understand and provides a good overview for decision makers, mid/top management and boards of directors. Further, for the sales representatives, the sales model and its implementation in a tool are easy to learn, understand and modify during sales projects. However, as mentioned earlier, training for the sales organization in value-based selling and how to explain the value to customers is necessary to achieve a good result. The outcome of the action research has led to permanent change in the three last cases, where the sales model is currently in use. In the last case, the sales model guides the sales process, assisting the sales representatives regarding what information to find and collect together with the customer. Further, in the last case, the new sales model and tool, being continuously further developed, are used for selling products, services, solutions and FP. In the two first cases, the sales model is no longer in use. The reasons for that are, among other things, the turnover of sales management/representatives and the fact that the sales model was not sufficiently stable, robust and easy to use at the time.

In case the business deals turn into non-profitable ones for either the selling party or the buying party, the sales model can be used to highlight this issue and to find a path to a win-win situation. However, this requires a very open, transparent and trustful business relation between the selling and buying party. 
This occurred sometimes during the third case, when the buying party wanted to lower the costs too much. However, the sales model assisted during the sales process to make the buying party realize that the selling party needed to have a certain level of profitability to create sustainable and long-term business.

Possibilities for improvements of the sales model found during the fifth case were creation and maintenance of master templates for different industries and scenarios, and that a light version of the sales model could, in some cases, be used at the start of a sales project to later shift to the full, advanced version.

As the number of respondents in the evaluation was only four, i.e. all involved in the sales activities, the outcomes of the rating scales alone are not enough to draw firm conclusions. However, considering the outcomes of the interviews and the rating scales, as well as the fact that the sales model and tool have led to permanent (and continuing) change in the last three cases, it is clear that the tested and verified model for value-based selling can be used for value-based sales of products, services, solutions and FP.

The tested and verified sales model extends Hanan \& Karp's (1991) proposed use of the NPV-method for estimating the expected rate-of-return by combining it with the PENG-model to be able to account for and price a fuller perceived customer value using a structured analysis. The latter is also in line with the process for finding and selling value proposed by Töytäri et al. (2011). The sales model further aligns with a conceptualization of valuebased selling in three dimensions (Terho el al., 2012), providing a structure and schedule, driving the sales process by stipulating what information needs to be collected and when, as well as when information should be disclosed to the customer. Töytäri et al. (2011 p493) rightly point out that the selling firms need to "support their sales efforts with tangible evidence of the value they can deliver to their customers, both pre-purchase as well as post-purchase". The tested and verified sales model can assist in doing both.

\section{Discussion and Conclusions}

This paper contributes to the advancement of the theory of value-based selling by presenting a tested and verified sales model, implemented in a tool, enabling value-based selling that takes into account direct, indirect and hard-to-estimate customer income/benefits (i.e. customer value). The sales model, which can support multiple business models, combines the PENGmodel and NPV-calculation, showing whether the business deal/investment fulfils the customers' requirement on rate-of-return (i.e. provides quantified customer value). 
The managerial implications of the paper are firstly that the proposed sales model can aid a standardized analysis of a customer's foreseen created/captured customer value by guiding the sales representative through the sales process (as in the five cases). Such a model, combined with sales training, prevents different approaches or interpretations of what a customer's perceived value comprises. In addition, among the sales representatives and sales management, an understanding of cash flow implications is necessary; otherwise, a sales project can do harm instead of good to the provider. Secondly, to avoid influences of cost- or competition-based pricing (Liozu et al., 2012) if and when members of the top management interact with customers, having a corporation's top management attend training in valuebased selling is likely a good idea. Nagle \& Hogan (2007) assert that value-based selling in combination with revenue-based incentives and sales representatives empowered to negotiate prices without a pricing policy can be toxic, poisoning the motivation to sell value. Thus, sales management involvement in the pricing process (use of which is proposed in this paper in favour of a pricing policy) and profit-based incentives can be necessary to avoid some of the pitfalls of value-based selling - and drive revenue with profit, instead of only revenue (Nagle \& Hogan, 2007).

As noted by Kowalkowski \& Kindström (2010) and Andersson et al. (2007), key is to visualize and manage customer value in sales projects and customer relations. The tested and verified sales model quantifies and visualizes the direct, indirect and hard-to-estimate income/benefits (i.e. customer values), and whether the wanted rate-of-return can be achieved. The projected income/benefits and rate-of-return can later be used to follow up on the actual results of a business deal or investment made, to manage the value expectations and ascertain whether any measures need to be taken. However, to find/identify, analyze/understand, estimate, model/simulate and quantify the values requires trust and transparency over time. Further, the value needs to be visualized and communicated to the customer (Terho et al., 2012) on a continuous basis, preferably by being able to, post-sales, provide tangible evidence of the value created/captured by the customer (Töytäri et al., 2011). It is of course not always possible to achieve trust and transparency, and in those sales projects the proposed sales model is hard or impossible to use and the value needs to be established by other means. The evaluation of the sales model further indicates that it is a good idea to dialogue with the buyer's top management (and in some cases the board of directors as well) and inform them as to the potential value that can be created/captured by the sales project, but allow those responsible for the 
technical and financial operations, instead of the top management, to drive and take the purchase decision. Otherwise, there is a risk for resistance or, at worst, a missed business opportunity. The sales model seems to support smaller customers more than larger ones, due to the fact that smaller customers are often not as adequately equipped as larger customers to prepare advanced business cases.

If the planned time of operation for what is offered is long (i.e. more than five years), naturally, it is hard to foresee exactly what will happen in the future and which customer values will be realized. If offering, for instance, a PSS/IPS ${ }^{2}$ or FP with provisioning of a function, the same goes for the costs which the provider needs to cover. Thus, to provide the best possible guidance for purchase decisions as well as sales decisions, it is important to be able to calculate and estimate the value, costs and cash flow impact for all involved parties.

An interesting question is whether there is a regional/cultural difference for use of value-based pricing, and in particular if it is accepted and that the necessary trust and transparency can be achieved. The sales projects during the five cases, where the proposed sales model was used, have mainly targeted Europe and the USA. However, the Middle East and Asia were also involved to a lesser extent. It seemed easier to approach new customers in Northern Europe and the Nordics compared to other regions, which may be due in part to the fact that the sales representatives were mainly from this area and thus knowledgeable on the regional and cultural specifics.

A reflection on the use of value-based selling is that it seems more appropriate for more complicated/complex offerings such as provisioning of productivity, result, availability or a function, where there is a higher degree of unique customer value (originating from intangibles) created/captured as well as potential customization, making the offer harder to compare on price alone. Off-the-shelf products or offers that are easy to compare with other offers are probably better sold based on cost and competition.

A further reflection is that when striving to sell productivity or a function, or using rental or leasing agreements, assets are not built up on the customer's balance sheet - assets are built up on the provider's balance sheet (unless some leasing partner is involved). On one hand, this keeps the customer's key ratios (performance indicators), such as return-on-assets or financial solidity, on the same level or improves them as the annual net result is positively impacted by the value yielded. On the other hand, the provider's key ratios involving assets are negatively affected by building assets and the provider 
needs to be supported by an increasing net result over time to create a sustainable win-win business situation. Thus, in scenario, with provisioning of productivity or a function, the provider needs to be compensated for the increased risk level, responsibility and building of assets to achieve a sustainable business.

Two of the three corporations using the proposed sales model have improved the structure of their sales processes (i.e. standardization) and are now able to better quantify and visualize the perceived customer value when interacting with decision-makers at customers. The use of the sales model further gives the sales representatives greater confidence, as well as creating a more professional impression among customers. The third corporation, which uses the model for investment assessments, has also changed its process similarly. The use of the sales model gives the corporations an advantage over the competition.

Finally, the tested and verified model for value-based selling introduced can enable corporations to add additional and more complex business models, where customer value increasingly originates from intangibles, by being able to quantify and visualize the perceived customer value while interacting and negotiating with customers. Thus, such a sales model can facilitate a transition from products or services towards solutions or additionally complex business models such as PSS/IPS ${ }^{2}$ or FP. However, there are both organizational and strategic challenges involved when implementing value-based selling which need to be addressed (Johansson et al., 2012). For corporations acting on global markets, an ability to add new and additionally complex business models can make the difference between decline and sustainable competiveness with profitability.

Regarding future research, it would be interesting to further improve the model for value-based selling in large global corporations, and to develop a scalable pricing process for globally distributed sales organizations.

\section{Acknowledgements}

The author would like to thank the five case corporations, and in particular the sales team at Infrafone AB, for their interest, close co-operation and valuable feedback.

Parts of the research in this paper were funded by the VINNOVA Excellence Centre the Faste Laboratory, Luleå University of Technology, Sweden, involved in FP innovation. 


\section{References}

[1] Alonso-Rasgado, T., Thompson, G. \& Elfström, B-O. (2004). The design of functional (total care) products. Journal of Engineering Design, 15(6), pp515-540.

[2] Anderson, J. C., Kumar, N. \& Narus, J. A. (2007). Value merchants: demonstrating and documenting superior value in business markets, $1^{\text {st }}$ edition. Harvard Business School Press, Boston, USA.

[3] Baines, T. S., Lightfoot, H. W., Evans, S., Neely, A., Greenough, R., Peppard, J., Roy, R., Shehab, E., Braganza, A., Tiwari, A., Alcock, J. R., Angus, J. P., Bastl, M., Cousens, A., Irving, P., Johnson, M., Kingston, J., Lockett, H., Martinez, V., Michele, P., Tranfield, D., Walton, I. M. \& Wilson, H. (2007). State-of-the-art in product-service systems. Proceedings of the Institution of Mechanical Engineers, Part B: Journal of Engineering Manufacture, October 1, 2007, Vol. 221, pp1543-1552.

[4] Brännström, O., Elfström, B-O. and Thompson, G. (2001). Functional Products create new demands on product development organizations. Proceedings of International Conference of Engineering Design, Glasgow, Scotland, 21-23 August, 2001.

[5] Casadesus-Masanell, R. \& Ricart, J. E. (2010). From Strategy to Business Models and onto Tactics. Long Range Planning, 43, pp195-215.

[6] Chesbrough, H. (2010). Business Model Innovation: Opportunities and Barriers. Long Range Planning 43, pp354-363.

[7] Coghlan, D., Coughlan, P. \& Brennan, L. (2004). Organizing for research and action: Implementing action research networks. Systemic Practice and Action Research, 17(1), pp37-49.

[8] Dahlgren, L. E., Lundgren, G. \& Stigberg, L. (1997). Make IT profitable!. Ekerlids Förlag AB, Stockholm, Sweden.

[9] Dahlgren, L. E., Lundgren, G. \& Stigberg, L. (2000). Öka nyttan av IT!: [att skapa och värdera nytta i verksamheten med hjälp av PENGmodellen]. Ekerlids Förlag AB, Stockholm, Sweden.

[10] Dahlgren, L. E., Lundgren, G. \& Stigberg, L. (2003). Öka nyttan av IT inom vården! Öka nyttan av IT!: [att skapa och värdera nytta i verksamheten med hjälp av PENG-modellen]. Ekerlids Förlag AB, Stockholm, Sweden.

[11] Dahlgren, L. E., Lundgren, G. \& Stigberg, L. (2006). PENG-modellen: Värderar och ökar nyttan av investeringar. Ekerlids Förlag $A B$, Stockholm, Sweden. 
[12] D'Andrea, R. (2005). Executing profitable sales negotiations: selling value, not price. Industrial and Commercial Training, 37(1), pp18-24.

[13] Fontana, A. \& Frey, J. (1994). Interviewing. In Denzin, N. and Lincoln, Y. (eds): Handbook of Qualitative Research, Sage Publications, Thousand Oaks, CA, USA.

[14] Grönroos, C., (2007). Service Management and Marketing: Customer Management in Service Competition, Third Edition. John Wiley \& Sons, Chichester, UK.

[15] Gummesson, E., (2000). Qualitative Methods in Management Research, 2nd Ed. Sage Publications, Thousand Oaks, CA, USA.

[16] Hanan, M. \& Karp, P. (1991). Competing on value. AMACOM, New York, USA.

[17] Johansson, M.W., Christensen, C.M., Kagermann, H. (1996). Reinventing Your Business Model. Harvard Business Review, NovemberDecember 1996, pp57-68.

[18] Johansson, M., Hallberg, N., Hinterhuber, A., Zbaracki, M. \& Liozu, S. (2012). Pricing strategies and pricing capabilities. Journal of Revenue and Pricing Management, 11(1), pp4-11.

[19] Kaufman, J.J. (1998). Value management: Creating Competitive Advantage. Best Management Practices Series, Crisp Publications, Menlo Park, CA, USA.

[20] Khalifa, A.S. (2004). Customer value: a review of recent literature and an integrative configuration. Management Decision, 42(5), pp645-666.

[21] Kindström, D. (2010). Towards a service-based business model - Key aspects for future competitive advantage. European Management Journal 28, pp479-490.

[22] Kotler, P. (2000). Marketing Management, The Millennium Edition. Prentice-Hall, Upper Saddle River, New Jersey, USA.

[23] Kowalkowski, C. \& Kindström, D. (2010). Value Visualization Strategies for PSS Development. In (eds) Sakao, T. and Lindahl, M., Introduction to Product/Service-System Design, Springer, London, UK.

[24] Kvale, S. \& Brinkmann, S. (2009). Interviews: Learning the Craft of Qualitative Research Interviewing. Sage Publications, Los Angeles, USA, pp159-181.

[25] Lindgren, P. \& Horn Rasmussen, O. (2013). The Business Model Cube. Journal of Multi Business Innovation and Technology, 1(3), pp135-182. 
[26] Lindström, J., Löfstrand, M., Karlberg, M. \& Karlsson, L. (2012). A development process for Functional Products: hardware, software, service support system and management of operation. International Journal of Product Development, 16(3/4), pp284-303.

[27] Lindström, J., Plankina, D., Nilsson, K., Parida, V., Ylinenpää, H. \& Karlsson, L. (2013). Functional Products: Business Model Elements. Proceedings of The 5th CIRP Conference on Industrial Product-Service Systems, Bochum, Germany, 14-15 March, 2013.

[28] Lindström, J., Sas, D., Lideskog, H., Löfstrand, M. \& Karlsson, L. (in press). Defining 'Functional Products' through their constituents. International Journal of Product Development.

[29] Lindström. J., Nilsson, K., Parida, V., Rönnberg Sjödin, D. \& Ylinenpää, H. (submitted). A value-based view on marketing and sales of Functional Products: An explorative study in manufacturing industry. Submitted to journal.

[30] Liozu, S. M., Hinterhuber, A., Boland, R. \& Perelli, S. (2012). The conceptualization of value-based pricing in industrial firms. Journal of Revenue and Pricing Management, 11(1), pp12-34.

[31] Little, B. (2012). Identifying key trends in sales - from a training perspective. Industrial and Commercial Training, 44(2), pp103-108.

[32] Löfstrand, M., Backe, B., Kyösti, P., Lindström, J. \& Reed, S. (2012). A model for predicting and monitoring industrial system availability. International Journal of Product Development. 16(2), pp140-157.

[33] Magnusson, C., Molvidsson, J. \& Zetterqvist, S. (2007). Value creation and return of security investments (ROSI). In (eds) Venter, H., Eloff, M., Labuschagne, L., Eloff, J. \& von Solms, R. New approaches for Security, Privacy and Trust in complex environments. IFIP International Federation for Information Processing, 232, pp25-35, Springer, Boston, USA.

[34] Meier, H., Roy, R. \& Seliger, G. (2010). Industrial Product-Service Systems-IPS ${ }^{2}$. CIRP Annals - Manufacturing Technology 59(2), pp607-627.

[35] Miles, M. \& Huberman, M. (1994). An Expanded Sourcebook Qualitative Data Analysis, $2^{\text {nd }}$ ed. Sage Publications, London, UK.

[36] Nagle, T. \& Hogan, J. (2007). Is your sales force a barrier to more profitable pricing ... or is it you?. Business Strategy Series, 8(5), pp365-368.

[37] Osterwalder, A., Pigneur, Y. (2010). Business Model Generation. John Wiley \& Sons Inc., New Jersey, USA. 
[38] Patton, M. Q. (1990). Qualitative Evaluation and Research Methods. Sage Publications, London, UK.

[39] Parvinen, P., Aspara, J., Hietanen, J. \& Kajalo, S. (2011). Awareness, action and context-specificity of blue ocean practices in sales management. Management Decision, 49(8), pp1218-1234.

[40] Rackham, N. \& DeVincentis, J. R. (1999). Rethinking the sales force: Redefining selling to create and capture customer value. McGraw-Hill, New York, USA.

[41] Reason, P. \& Bradbury, H. (Eds.) (2001). Handbook of action research: Participative inquiry and practice. Sage Publications, London, UK.

[42] Schuh, G., Klotzbach, C., Gaus, F. (2008). Service provision as a submodel of modern business. Production Engineering 2(1), pp79-84.

[43] Stahel, W. (1997). The Functional Economy: Cultural and Organizational Change. In Richards, D. J. (eds), The Industrial Green Game: Implications for Environmental Design and Management. National Academy Press, Washington DC, USA.

[44] Stufflebeam, D. L. (2001). Evaluation Models: New Directions for Evaluation, 89, Jossey-Bass / John Wiley \& Sons, USA.

[45] Teece, D. J. (2010). Business Models, Business Strategy and Innovation. Long Range Planning, 43, pp172-194.

[46] Terho, H., Haas, A., Eggert, A. \& Ulaga, W. (2012). 'It's almost like taking the sales out of selling' - Towards a conceptualization of valuebased selling in business markets. Industrial Marketing Management, 41, pp174-185.

[47] Töytäri, P., Brashear Alejandro, T., Parvinen, P., Ollila, I. \& Rosendahl, N. (2011). Bridging the theory to application gap in value-based selling. Journal of Business and Industrial Marketing, 26, pp493-502.

[48] Van Ostaeyen, J., Kellens, K., Van Horenbeek, A. \& Duflou, J. R. (2012). Quantifying the economic potential of a PSS: methodology and case study. Proceedings of the $4^{\text {th }}$ CIRP International Conference on ProductService Systems, 8-9 $9^{\text {th }}$ November, 2012, Tokyo, Japan. 


\section{Biography}

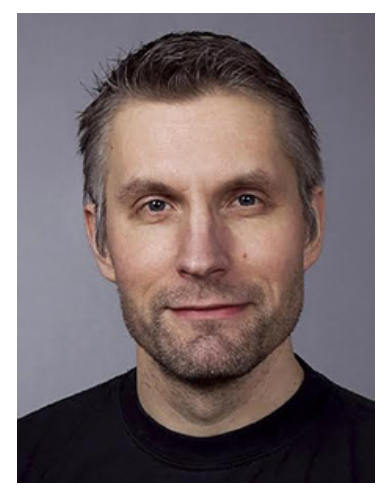

John Lindström, Associate Professor EMBA CISSP, received his $\mathrm{PhD}$ in Information Systems Science at Luleå University of Technology, Sweden. Currently, John is CEO for the Process IT Innovations R\&D Centre spanning Luleå University of Technology and Umeå University, Sweden. John's research interests include business modelling, development processes, availability matters on system and organizational level, as well as modelling and simulation applied in industrial development processes. One of his main research interests lies in the area of product development for function provision, i.e. Functional Product development. Prior joining academy in 2009, he worked for 15 years in different industries in both management and specialist positions with product-, service-, process-, and business development. 
